\title{
LIFETIME IMPACT PREDICTION OF COMPONENT MODIFICATIONS IN AXIAL PISTON UNITS BY THE FAILURE LIKELIHOOD ASSESSMENT
}

\author{
Ivan Baus ${ }^{1 *}$, Robert Rahmfeld ${ }^{1}$, Andreas Schumacher ${ }^{1}$, Henrik C. Pedersen ${ }^{2}$ \\ ${ }^{1}$ Danfoss Power Solutions, Krokamp 35, 24539 Neumünster, Germany \\ ${ }^{2}$ Aalborg University, Department of Energy Technology, Pontoppidanstraede 111, 9220 Aalborg \\ *Corresponding author:Tel.: +494321871731,E-mail:ibaus@danfoss.com,ivb@et.aau.dk
}

\begin{abstract}
In this paper, a new methodology is presented to estimate the lifetime impact of design changes, called Failure Likelihood Assessment (FLA). The discussion in this paper is on the fatigue lifetime prediction of axial piston units, especially after a design change. The demonstration object is an axial piston pump due to extreme environmental conditions and high specification demands, where the FLA is applied to a manufacturing change in an existing product and delivers an effect on the unit reliability. The resulted reliability improvement, if combined with typical calculation methods like Weibull analysis, delivers an increase in predicted lifetime considering the intended modification. As demonstration subject, a change of the manufacturing process of the cylinder block hub in an axial piston pump is used. The effect to the lifetime is predicted via the FLA-method and the results are calculated with test data and compared to theoretical results. The paper shows that the methodology delivers highly accurate results providing that the FLA is a powerful tool to analyze design changes as well as new designs in regard to reliability and lifetime. The benefit for the user of this methodology will hence be more reliable products with optimized designs to best fulfil customer's performance requirements.
\end{abstract}

Keywords: Axial Piston Units, Reliability Assessment, Lifetime Prediction, Drivetrain, Design

\section{INTRODUCTION}

Appropriate functioning of an axial piston unit is fundamental to every operation of a drivetrain system in an off-road application. To ensure the proper function and/or to observe the reliability of a system, the market trend is growing in case of condition monitoring. The current trend in many different research fields shows a big focus on condition monitoring and real-time prediction of service life [1,2]. This trend is generally forced by the uptime-efficiency requirements of today's products. The uptime-efficiency is in this regard defined as the optimal use of the service life before a relevant failure occurs and is depended on the accurate knowledge of the risk versus reliability mechanisms, which aids/ results in lifetime prediction values. A proper risk assessment methodology leads to an accurate prediction of a failure and downtime reduction of a system, whereby the reliability of lifetimerelevant system components is playing the main role [3]. The prediction research may be divided mainly in two different groups: offline and online concepts. The online prediction includes a.o. realtime condition monitoring, fault detection and diagnostics concepts like e.g. fault detection by learning algorithms or threshold diagnostics. These methods are typically used on board of a vehicle $[4,5]$. An actual research in field of online lifetime analysis is the work of Mr. Brinkschulte, where the development of the damage reduction strategy for mobile machines is connected to the intelligent identification of the machine operator is in focus [6]. On the other side are the offline methods, which include theoretical calculation tools like the prediction of the fatiguerelevant lifetime or product reliability analysis during the development or redesign phases. These offline methods and the FLA methodology are in focus of this work sequel, where this paper covers the impact analysis of a manufacturing change. Especially in case of fatigue-relevant analysis of the lifetime, different theoretical methods are in use. This long-term phase of a product lifecycle is described in the last stage of 
the bathtub curve and represents an increasing failure rate, where the reliability tends toward zero [7]. Beside the fatigue-focused analysis the friction-relevant research is playing an important role in lifetime analysis, where a.o. an actual work was published by L. Brinkschulte [8].

Performing a system analysis with theoretical methods and the related evaluation of occurred results is often difficult due to the complexity of axial piston units. The complexity further increases from the system requirements, not least due to the integration into off-road applications which are subject to a high combination of variable load factors in the field $[9,10]$.

Additionally, when developing new products, field data rarely exist (e.g. load spectrum or environment conditions), why the methods require proper experience with previous product loads. Here an improper approximation or a wrong estimation of relevant factors/loads may lead to a deviation in the lifetime prediction. Thus, precise theoretical methods with high accuracy in prediction avoid negative impact on the uptime. The state-of-the-art theoretical methods, which are typically used, are a.o.:

- Weibull Analysis [7]

- SN / Wöhler curve [11]

- Palmgren-Miners Rule [12, 13]

- Mean Time to Failure (MTTF) [14]

- System State Enumeration [15]

- WeiBayes / Zero Failure Test [16, 17]

A typical result of these lifetime calculation methods is defined as $L_{10}$ (theoretical nominal lifetime), where the first $10 \%$ of a product lot would theoretically fail. These methods, which have existed for decades, normally deliver conservative results, like seen in field and test lab data. Therefore, in previous work a new methodology so-called FLA was developed and evaluated by field data to improve the accuracy of the lifetime prediction [18]. Hence, this work is a sequel of the lifetime research and the purpose of the current work is a demonstration of the Failure Likelihood Assessment methodology (FLA) as a means in impact analysis of a design change in case of lifetime prediction. A typical procedure for lifetime evaluation includes the definition of the product characteristic and the applied load. These factors are used as a basis for calculating the lifetime. Afterwards, the values may be verified in a test lab by using the Weibull analysis [17]. Hence, the practical analysis of lifetime relevant values/coefficients covers test lab evaluation by endurance or other qualification tests [19-22].

The current work here focuses on the Weibull or more specifically the fatigue-related SN-curve analysis in combination with FLA feasibility. This is especially in connection to the lifetime prediction and reliability analysis after a design change. Thus, the proceeding of the FLA results in a change of the reliability curve after a specific design change, which can be applied to the lifetime calculation. The impact of a design change is directly linked to the lifetime calculation based on the Weibull-analysis.

A demonstration of the experimental data acquisition and the FLA analysis is presented, which is based on an exemplarily applied change of the manufacturing process of the cylinder block hub used in an axial piston pump. Here the issues of the experimental testing are discussed as well. Hence, an analysis based on experimental acquisition of the failure rate has been performed, where $B_{10}$ is defined as experimental nominal lifetime and is typically used in the market as the reference value for different purposes, like e.g. maintenance management. In this case, a test lab setup was developed, and the results from the experiments were analyzed. Here, an applicationspecific load equivalent is playing an important role as the boundary condition. Due to the practical and economical limitations of the experimental analysis, the FLA analysis follows as a statistical approach. The extended analysis combines the experimentally-determined failure probability with the reliability change of the previously mentioned manufacturing change of a cylinder block hub. The FLA-extended Weibull calculation with the failure probability allows a highly accurate lifetime prediction. Finally, the FLA validation concludes the work by using process data of the part manufacturer.

\section{STATE-OF-THE-ART CALCULATION OF THE LIFETIME}

The general goal of each engineer is a reliable product with optimal design margin according to the state-of-the-art requirements, which at the same time has a high economic efficiency. Not least, the focus of the engineer should be at a proper design of fatigue-relevant components so that the lifecycle of the affected product is fulfilling the requirements. In case of dynamic 
loads, a load equivalent is connected to the fatigue strength of a component. The equations typically used for lifetime analysis and failure rate evaluating in mechanical systems and parts are the following:

$$
\begin{array}{lr}
\text { Weibull reliability: } & R(x)=e^{-\left(\frac{x}{\eta}\right)^{\beta}} \\
\text { Miner's Rule: } & X=\sum_{i=1}^{I} \frac{n_{i}}{N_{i}} \leq 1 \\
\text { SN curve: } & L_{10}=\left(\frac{C}{P}\right)^{k}
\end{array}
$$

The mathematical correlation of stress (typically called duty cycle, load spectrum or load equivalent) with fatigue strength build the essential part of the SN-curve analysis. Thus, degradation of the component strength against dynamic loads or rather the damage accumulation is analyzed. In particular, it is desirable that under different types of loads, e.g. axial tensilecompression or bending and torsional stress, the calculation accuracy of the lifetime prediction can be achieved by high statistical certainty. The accuracy of the lifetime calculation thus depends strongly on knowledge about the damage accumulation, load spectrum and fatigue strength of a component.

These mathematical hypotheses, the so-called linear damage accumulation hypotheses, are used to calculate the lifetime of components, where $k$ is defined as the lifetime exponent of the SNcurve and may be drawn as a straight line in a double logarithmic plot, like it can be seen in Figure 1. The scientific significance of the predicted results is on the evaluation by experimental and theoretical analysis and depends crucially on the nature of the mathematical accumulation rule. Normally, the objective of lifetime research is to provide

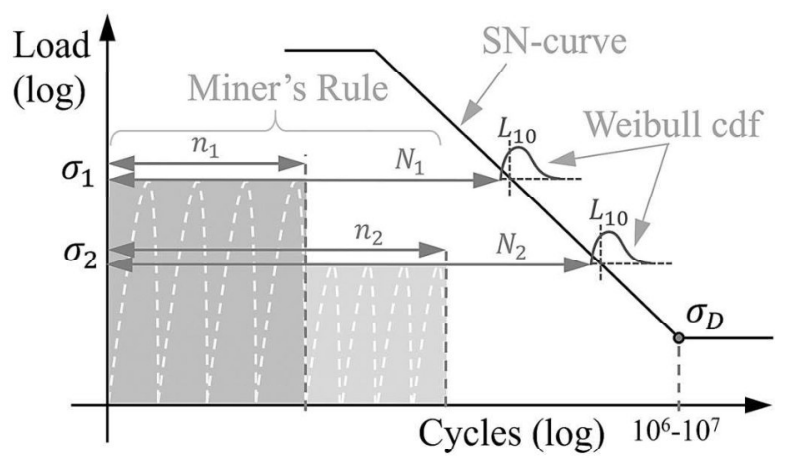

Figure 1: Lifetime calculation according to linear damage accumulation customers and engineers with an improved approach for predicting lifetime. Thus, the comprehensive load spectrum determination is playing a very important role and should be taken into account. Significant improvements have been made to the well-known linear PalmgrenMiner hypothesis (Miner's Rule) by the use of exponential damage approaches $[12,13]$. In general, new theoretical approaches must be analyzed with regard to accuracy and parameters, where the influencing factors or rather the impact must be determined twice: quantitatively and qualitatively.

However, the theoretical results deliver shorter lifetime values compared to what is experienced in the field or test lab: different endurance tests like "steady-state"- and "flywheel"-tests show that the state-of-the-art prediction methods deliver conservative results. Therefore, more reliable and precise prediction methods are required. Thus, the FLA method was developed and validated in a previous work of the current authors. The validation of the method was done by using field data and did show successful and accurate results in different cases of reliability research [18].

\section{SN-CURVE ANALYSIS OF COMPLEX SYSTEMS IN PRACTICE}

An axial piston unit consists of many different components, which are affected by different load factors like temperature, rotation speed, pressure, friction, vibration and others. This very complex environment makes it difficult to analyze a specific sub-component separately. Therefore, an axial piston unit is typically tested as a complete system in case of endurance or evaluation testing, even if only one single component has changed.

The problem is that Miner's Rule or rather the SN-curve analysis only considers one dynamic load applied to one component only. Otherwise, the combination of many dynamic factors in an evaluation approach may create an infinite value of unknown conditions. This fact leads to a need for endurance testing concepts, where the testing conditions can be taken into account as a constant load of the whole system, where the components in rotation e.g. kit-subsystem are affected by alternating load, as shown in Figure 1.

An additional issue in case of the lifetime analysis is the experimental acquisition of the failure probability by low loads. Normally, the 


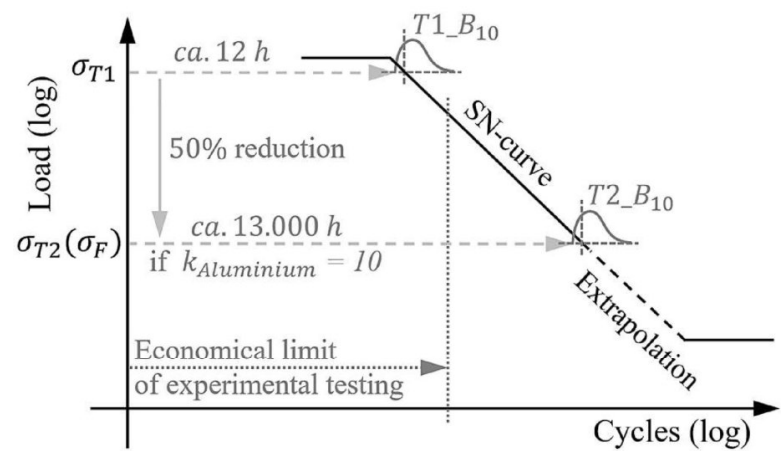

Figure 2: Experimental data acquisition vs. theoretical extrapolation of the SN-curve

financial aspect of the testing is very sensitive due to the proportional connection of testing costs to the lifetime exponent $k$, as shown in Figure 2, where the lifetime exponent $k$ can be seen as the $\mathrm{SN}$-curve gradient in a log-log chart. Therefore, from an economic point of view, an experimental approach could take too much time in some cases. If an application in the field does require an experimental evaluation at the existing load equivalent, this could lead to high testing costs, which can be calculated with (4).

$$
\left(\frac{\sigma_{T 2}}{\sigma_{T 1}}\right)^{k} \frac{\text { Price }[h]}{\text { rpm } \cdot 60}=\text { Price }[\text { run }]
$$

To demonstrate an economical issue more detailed an illustrative load spectrum is shown in Table 1, where a load example of a drivetrain application is illustrated as pressure ratio. This example covers a typical loading cycle of a wheel loader, also known as the standardized Y-cycle [23]. Here, the load equivalent in field is seldom higher than $50 \%$ of max. strength (if $\sigma_{F}$ covers the system pressure) like shown in Figure 2. Here the $\sigma_{F}$ is the calculated load equivalent defined as the Root Mean Effective Pressure (RMEP), while the economical limit in this picture is an illustrative assumption only.

Table 1: Load ratio of a wheel loader

\begin{tabular}{|c|c|c|c|c|r|r|r|r|r|}
\hline ratio & $35 \%$ & $18 \%$ & $12 \%$ & $12 \%$ & $11 \%$ & $6 \%$ & $3 \%$ & $2 \%$ & $1 \%$ \\
\hline$\Delta \mathrm{p}[\mathrm{bar}]$ & $0-40$ & $<80$ & $<120$ & $<160$ & $<200$ & $<240$ & $<280$ & $<320$ & $<360$ \\
\hline$\sigma_{F}$ & \multicolumn{10}{c|}{ ca. $\mathrm{p} \_\max \cdot 0,5$} \\
\hline
\end{tabular}

The endurance testing in such conditions $\left(\sigma_{T 2}=\sigma_{F}\right)$ would require ca. 13.000 hours per failure if the testing object is made of aluminum. Considering that more than one failure event is required for a sufficient confidence in statistical methods, the costs are also connected to the number of required failure events as well. The environmental conditions and the cost factors represent a big challenge, which requires a high level in accuracy of theoretical analysis methods.

\section{EXPERIMENTAL ACQUISITION OF $B_{10}$}

In this chapter, an experimental setup is described, which includes the determination of $B_{10}$. Industry-used $B_{10}$ value is defined as the experimentally-investigated lifetime point, where the first $10 \%$ of a product lot would fail by the applied load. This value is also used as the reference for the reliability calculation of the FLA, see next chapter. The aim of this test setup is the analysis of the product-specific failure rate. Hereby, the focus is on the Weibull slope and SNcurve gradient.

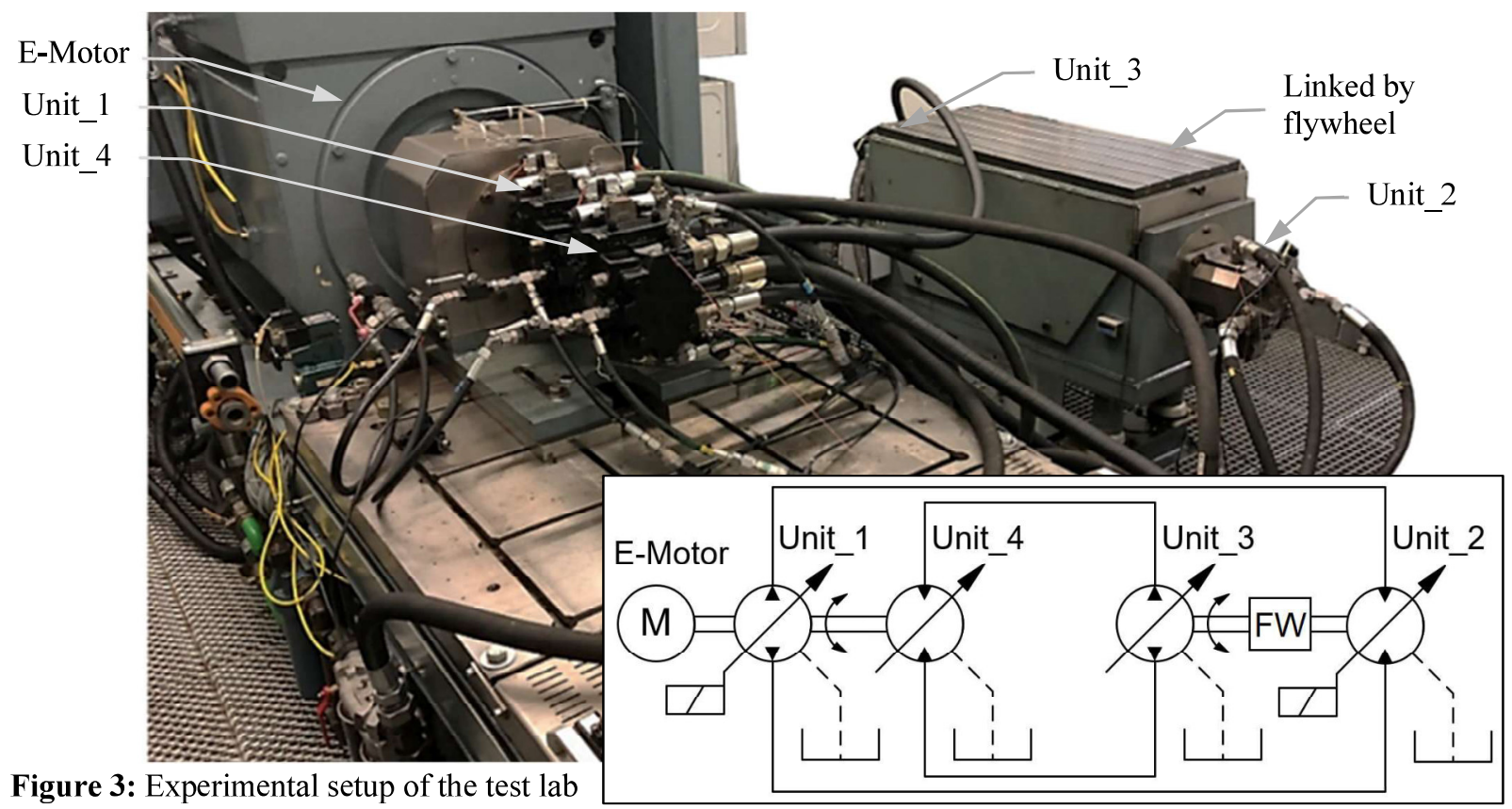


The steady-state conditions were defined for two constant load levels as shown in Figure 2 as $\sigma_{T 1}$ and $\sigma_{T 2}$. Both conditions were set before the economical limit. The difference between both conditions was only the system pressure which describes the load factor. All other factors like temperature, speed etc. were constant. The setup between the units did realize the following hardware situation as shown in Figure 3.

- Unit_1 in pumping mode

- Unit_2 in motor mode

- Unit_3 in pumping mode

- Unit_4 in motor mode

These different modes are typically present in the field as well, where different load scenarios for the components do exist and also have to be addressed by the lifetime investigation in general. In this paper, only results of the Unit_1 are shown for illustration purposes.

The results of the endurance testing can be seen in Figure 4, where the X-axis represents the cycles $(x)$ before a failure occurs and the $\mathrm{Y}$-axis represents the unreliability $(F(x))$ of the tested component. Subsequent results of the Weibull analysis deliver specific values like $\eta$ or $\beta$. Eta $(\eta)$ is defined as the characteristic lifetime at $63,2 \%$ of the unreliability, while Beta $(\beta)$ is defined as the Weibull slope and shown as gradient of the $50 \%$ confidence line in Figure 4. Both values do characterize the lifetime behavior of the tested

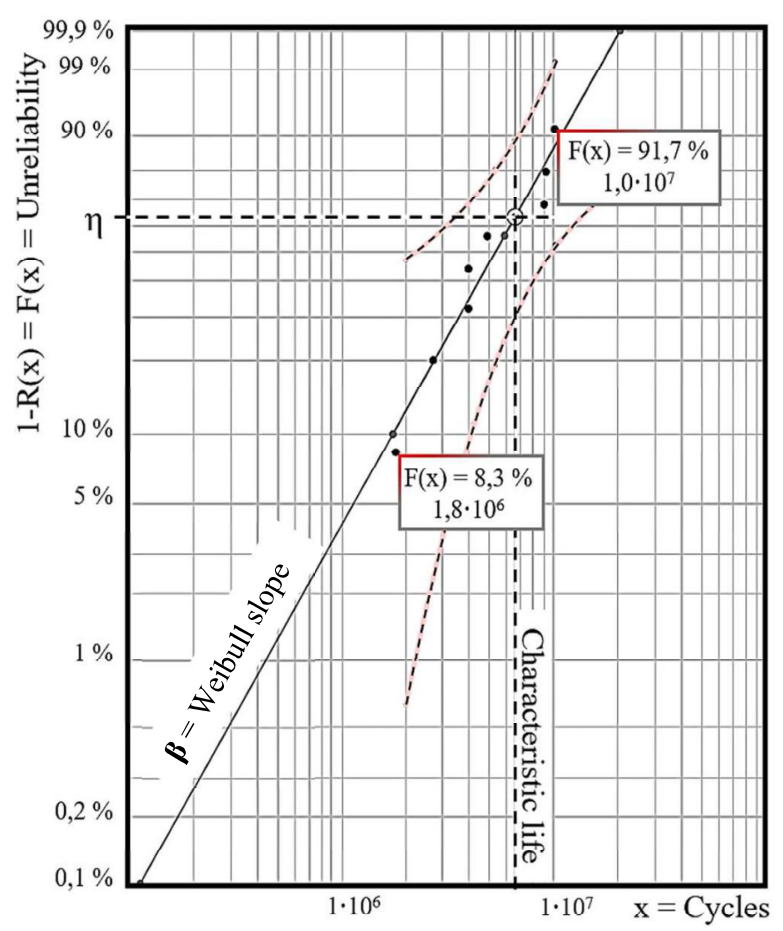

Figure 4: Weibull probability plot (90\% confidence) component. The characterization covers a.o. the reliability curve, which is used as the reference curve for the next step of the FLA connecting calculation.

\section{ANALYSIS BY USING OF THE FAILURE LIKELIHOOD ASSESSMENT}

The FLA method combines two (industrial-used) standard methods, Fault Tree Analysis (FTA) and Failure Mode and Effect Analysis (FMEA). Thus, the analysis of the risk assessment is based on a failure propagation (FTA) and a quantitative assessment (FMEA), where the main advantages are: identification of all possible failure causes, failure propagation in the present/defined system, identification of its reliability and detection of the weak link ranking [18].

The core steps of the methodology are shown in Figure 5. Here the first step is the "System definition" of the investigated system. Standard documents/sheets like exploded views or circuit diagram makes it easy to apply this methodology to many different sub-systems. In this paper, a change in the manufacturing process is used as calculation and evaluation example.

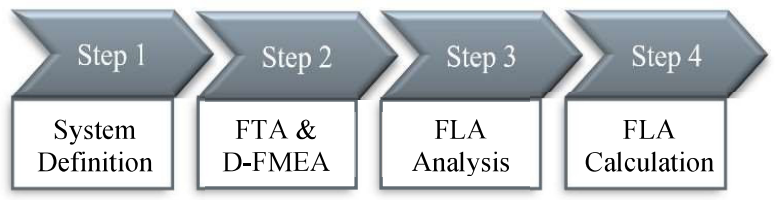

Figure 5: FLA Analysis proceeding phases/steps

An exploded-view as shown in Figure 6 allows selecting an appropriate detail level, according to the focus of the requested investigation topic. The FTA tree allows covering the whole system, starting by the top-level through sub-assemblies and components down till material and environmental conditions.

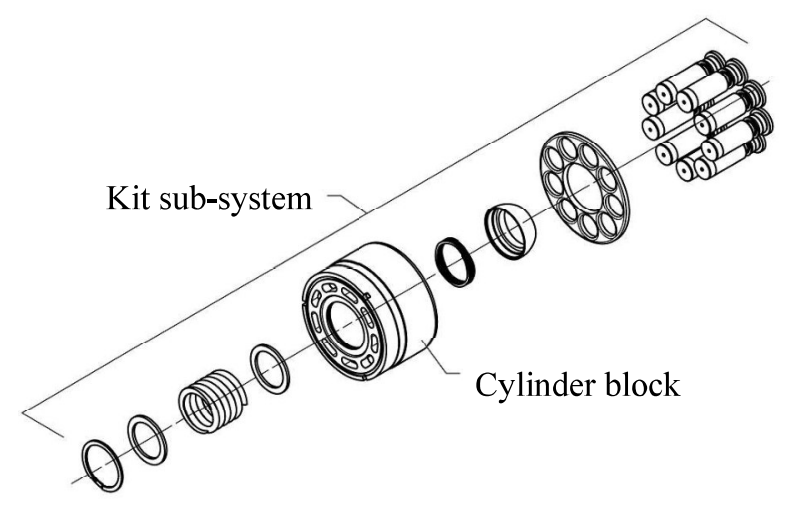

Figure 6: Exploded view of a kit sub-assembly 


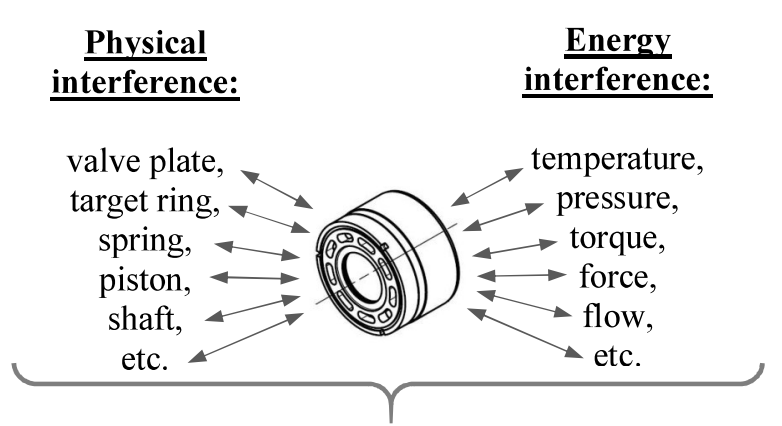

D-FMEA table of cylinder block

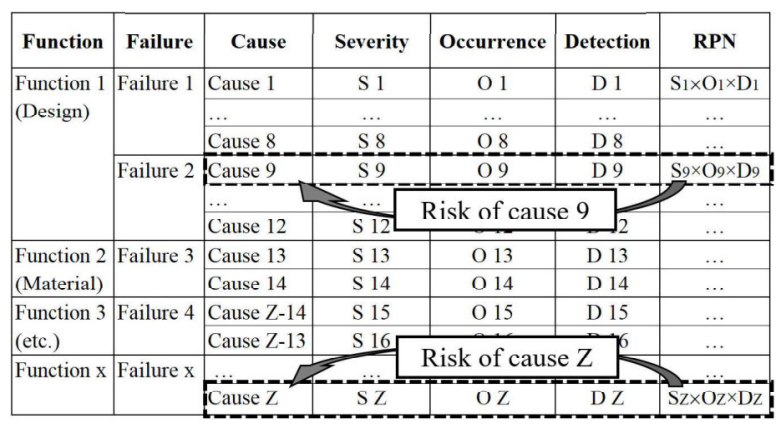

Figure 8: Risk analysis (conventional D-FMEA)

The second step is the definition of the functions and potential failures. Thus, the recommendation is to use both FTA and DesignFMEA in alternating sequence to avoid gaps in the investigation, which leads to corruption of the reliability assessment. As soon as the system is defined, the sub-levels (function, failure and cause) are drawn, the completeness of the fault tree is verified by the FMEA structure/tables, and the risk analysis can move to the third step.

The result of the third step consists of a propagation overview as a fault tree structure with quantitative nodes or rather occurrence nodes as seen in Figure 7. The previous methods/ tools like FTA or D-FMEA would deliver only an incomplete picture of the intended change. In case of the FTA, only a fault tree without a possibility of quantitative assessment would exist, while the D-FMEA would deliver the Risk Priority Number (RPN) of each single cause without a relation to the relative lifetime impact of the change, like shown in Figure 8, where the RPN is typically calculated by using severity $(S)$, occurrence $(O)$ and detection $(D)$ [24]:

$$
R P N_{\text {cause }}=S \times O \times D
$$

In case of the cylinder block demonstration example, the change covers a surface treatment process, where the manufacturer predicted a significant improvement $\left(\Delta \boldsymbol{L}_{10 M}=30 \%\right)$ of the fatigue strength. Hence, the FLA was calculated at a single component only and deliver the reliability values of the applied change, like shown in Figure 7. Here the number of causes and the corresponding occurrence values were determined from the occurrence-table and propagation-tree, especially related to sub-tree of the cylinder block.

The results of the fourth step conclude in weighted occurrence values of the manufacturing change, which can be seen in Equations (7) and (8). The weighting of the occurrence is related to the number of applied causes, where a high number of causes or rather a high failure amount has a high impact on the investigated system. In case of the FLA, only the occurrence of the causes is taken into account due to the previous evaluation of the FLA method related to the relevance and best-fit impact of the occurrence [18]. The derivation of the weighted occurrence as an appropriate value for the FLA analysis is based on the definition and the cross-connection

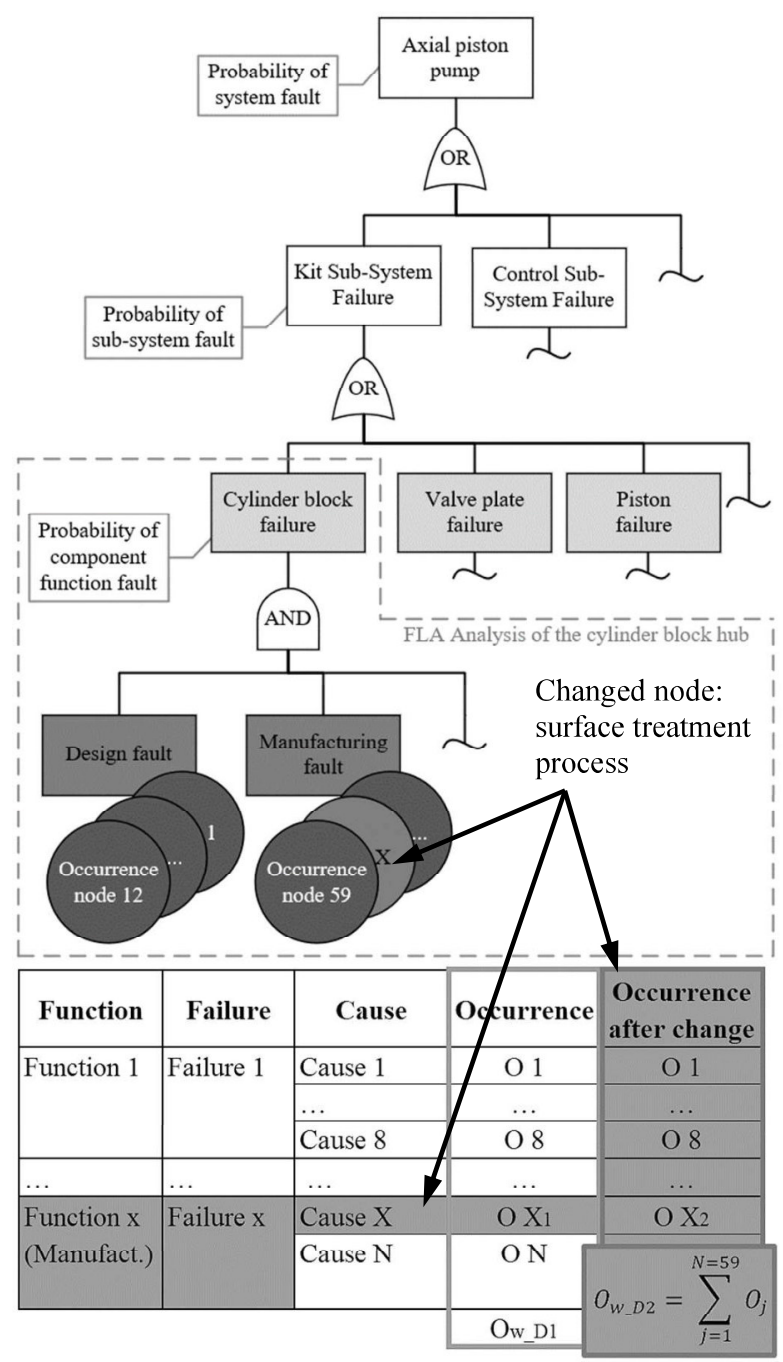

Figure 7: Failure Likelihood Assessment (FLA) 
of the failure probability in all FLA-relevant methods:

\section{D-FMEA}

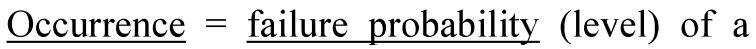
specific cause.

\section{FTA}

Failure propagation $=$ failure probability in a system (relative)

\section{Weibull analysis}

Unreliability $=\underline{\text { failure probability }}$ related to the number of cycles

Therefore, the FLA allows calculating the failure probability or rather the reliability for the given sub-structure. The results can be seen below, where $N_{D 1 / 2}=59$ is the number of causes and the $O_{w_{-} D I / 2}$ is the weighted occurrence of a specific change. The reference part is marked with $D 1$ while the changed part is marked with $D 2$. After the manufacturing modification $N$ is unchanged as the number of causes stay the same. Only the occurrence has changed due to the engineering assessment.

$$
\begin{gathered}
N_{D 1}=N_{D 2}=59 \\
O_{w_{D 1}}=\sum_{\substack{j=1 \\
N=59}} O_{j}=145 \\
O_{w_{D 2}}=\sum_{j=1}^{N=59} O_{j}=138
\end{gathered}
$$

The design improvement is calculated below in (9) and is used as a positive reliability change of the product if the outcome is positive:

$$
\underbrace{}_{\text {FTA Impact }}=\left(\begin{array}{c}
N_{D 2} \cdot O_{w_{D 1}} \\
N_{D 1} \cdot O_{w_{D 2}}
\end{array}\right) \cdot 100 \%=5,1 \%
$$

Weibull link

This reliability improvement was added to the experimentally-derived results, where the failure rate of the experimental data was used as the reference curve. The reliability improvement $\Delta R$ was applied to the $B_{10}$-characteristic point, which is defined as experimentally-determined nominal lifetime, where $10 \%$ of units may fail, as it can be seen in Figure 9. Here the reliability $R(x)$ of the product is equal to $90,4 \%$. The calculated nominal life after change is therefore defined as

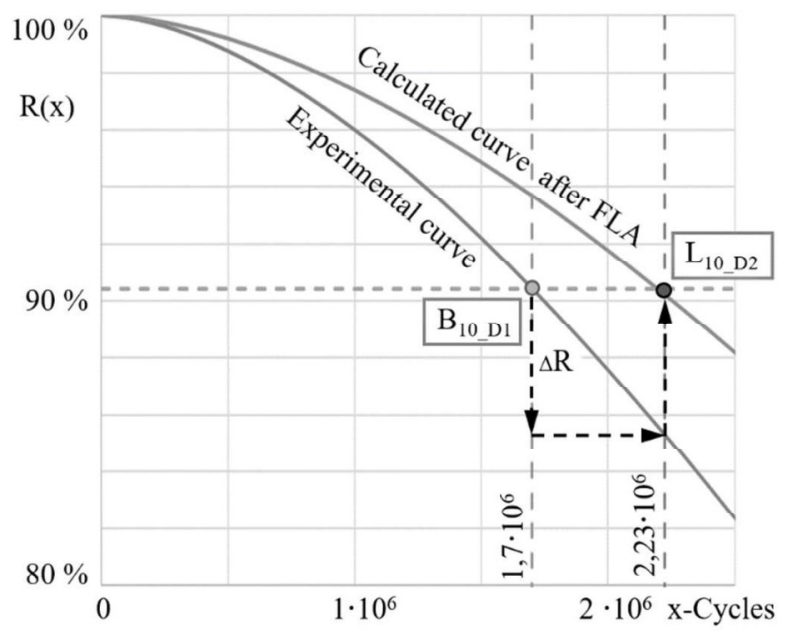

Figure 9: Experimental and calculated reliability

$L_{10} D 2$ and deliver a new reference for the lifetime, where $10 \%$ of units may fail according the Weibull density function. The comparison of the $B_{10 D D 1}$ (before change) and $L_{10} D 2$ shows that the change gives a significant improvement in lifetime. The potential of the improvement can be calculated with the following:

$$
\Delta L_{10 F L A}=\left(\frac{L_{10_{D 2}}}{B_{10_{D 1}}}-1\right) \cdot 100 \%=31 \%
$$

Hence, this specific engineering change in the manufacturing process may improve the fatigue strength or rather the lifetime of the component by $31 \%\left(\Delta \boldsymbol{L}_{10 F L A}\right)$. The difference between the specification value of the manufacturer and the FLA-calculated results $\left(\Delta L_{10 F L A}-\Delta L_{10 M}\right)$ is remarkably small. This result can be applied to the whole SN-curve, so that the effect for different load spectra or equivalents (application characteristics) can be precisely predicted. Thus, each D-FMEA change can be precisely analyzed related to the change in lifetime and allows a better impact understanding of manufacturing, design and/or other changes.

\section{CONCLUSION}

In this work, the failure rate of a cylinder block under certain conditions was experimentally determined, with the focus on the fatigue strength analysis. Thus, the experimental feasibility and its issues like the economic aspects were discussed as well. It is obvious that a new or improved theoretical approach is required. The accuracy of the theoretical prediction was in focus, where a new methodology the so-called Failure Likelihood Assessment (FLA), was 
applied. This failure assessment method is based on the FTA and D-FMEA as standards tools. Thus, the FLA is a systematical method which combines the failure propagation in a system with the quantitative characteristics and therefore allows a calculation of the failure probability or rather the reliability of a system. The FLA method was applied to a manufacturing change of the cylinder block. The relation between FLA and change evaluation was taken in account, where the advantages of the connection to the load equivalent in the field were shown. The results showed that the FLA methodology delivers accurate results so that it becomes a powerful tool to analyze design changes as well as new designs in regard to reliability and lifetime prediction already in the early design phase. The accuracy increase in calculation improves the lifetime prediction and thereby supports the fulfillment of customer requirements. More reliable product with an optimized design is here the benefit for the user of this methodology.

\section{OUTLOOK}

An experimental evaluation of both, the FLAcalculated and manufacturer-specified values are the next steps. Moreover, the FLA feasibility to different change types in a multi-component system will follow in the succeeding researches. The focus will be on analysis of the system and component reliability related to the lifetime. Especially, the connection between a design change and lifetime impact in a system will be addressed here.

\section{NOMENCLATURE}

$\begin{array}{ll}F(x) & \text { Unreliability (in cycles) } \\ R(x) & \text { Reliability (in cycles) } \\ \Delta R & \text { Reliability improvement } \\ L_{10} & \text { Calculated Nominal Lifetime } \\ \Delta L_{10 F L A} & \text { FLA-Calculated Lifetime Improvement } \\ \Delta L_{10 M} & \text { Manufacturer-Predicted Lifetime Improv. } \\ B_{10} & \text { Experimental Nominal Lifetime } \\ x & \text { Cycles Bevore Failure } \\ \beta & \text { Weibull Slope } \\ \eta & \text { Characteristic Lifetime } \\ n & \text { Occurred Number of Cycles } \\ N & \text { Maximum Number of Cycles (Miner's Rule) } \\ X & \text { Linear Damage Accumulation } \\ N_{D 1} & \text { Number of Root Causes (First Design) } \\ N_{D 2} & \text { Number of Root Causes (Second Design) }\end{array}$

$\begin{array}{ll}k & \text { Gradient of the Lifetime Curve } \\ C & \text { Dynamic Load } \\ P & \text { Equivalent Dynamic Load } \\ \sigma_{X} & \text { Load at Level X } \\ \sigma_{T X} & \text { Load of Testing Number X } \\ \sigma_{F} & \text { Load equivalent in Field } \\ O_{w D 1} & \text { Weighted Occurrence (First Design) } \\ O_{w D 2} & \text { Weighted Occurrence (Second Design) } \\ \Delta p & \text { System Pressure } \\ P_{-} \text {max } & \text { Maximum Pressure }\end{array}$

\section{ABBREVIATIONS}

$\begin{array}{ll}R M E P & \text { Root Mean Effective Pressure } \\ F L A & \text { Failure Likelihood Assessment } \\ c d f & \text { Comulative Density Function } \\ T 1_{-} B_{10} & \text { Test with condition 1 } \\ T 2_{-} B_{10} & \text { Test with condition } 2 \\ S N & \text { Stress related to Number of cycles } \\ F T A & \text { Fault Tree Analysis } \\ D-F M E A & \text { Design-Failure Mode and Effect Analysis } \\ R P N & \text { Risk Priority Number } \\ S & \text { Severity } \\ O & \text { Occurrence } \\ D & \text { Detection } \\ D 1 & \text { Design 1 (before change) } \\ D 2 & \text { Design 2 (after change) }\end{array}$

\section{REFERENCES}

[1] Bauer J. A., Wang M., Yaun Q., Gust M. "Automation, Connectivity and Big Data in Fluid Power Systems and Off-Road Vehicles." Symposium of Fluid Power and Motion Control (GFPS), Sarasota, USA, October $9^{\text {th }}, 2019$

[2] Boog, M., "Steigerung der Verfügbarkeit mobiler Arbeitsmaschinen durch Betriebslasterfassung und Fehleridentifikation an hydrostatischen Verdrängereinheiten". Karlsruhe Institute of Technology, PhD thesis, 2010.

[3] Martin K. F., "A review by Discussion of Condition Monitoring and Fault Diagnosis in Machine Tools", Int. J. Mach. Tools Manufact. Vol. 34, No. 4, 1994

[4] Fusko M., Rakyta M., Krajcovic M., Dulina L, Gaso M., Grznar P., "Basics of Designing Maintenance Processes in Industry 4.0", University of Zilina, Faculty of Mechanical Engineering, Department of Industrial Engineering, Zilina, Slovak Republic, DOI: 10.17973/MMSJ.2018_03_2017104, ISSN 1805-0476, 2018

[5] Liu X., Cui D., Wang L, Zhang L, "Reliability Evaluation of Hydraulic Pump Based on 
Performance Degradation", 11th International Fluid Power Conference (IFK 2018), Aachen, Germany, 2018.03.19-21

[6] Brinkschult, L., Mattes J., Geimer, M. "An approach to wear simulation of hydrostatic drives to improve the availability of mobile machines." 11th International Fluid Power Conference (IFK), Aachen, 19.-21. März 2018. Vol. 1. Ed.: H. Murrenhoff, 392-407, RWTH Aachen University, Aachen. doi:10.18154/ RWTH-2018-224523, 2018

[7] Weibull, W., "A statistical distribution function of wide applicability", Journal of Applied Mechanics, pp. 293-297., 1951

[8] Brinkschulte L., Geimer M., "Intelligent Machine Operator Identification to Develop Damage Reducing Operating Strategies for Mobile Machines", Symposium of Fluid Power and Motion Control (GFPS), Sarasota, USA, October 9th, 2019

[9] Lorösch, H.-K., "Die Gebrauchsdauer von Wälzlagern hängt nicht nur von der Tragzahl ab", Wälzlagertechnik - Industrietechnik (FAG), S15-21, 1992

[10] Kunze, G., "Methode zur Bestimmung von Normlastkollektiven für Bau- und Fördermaschinen - Lebensdauerabschätzung an Baugruppen von Bau- und Fördermaschinen." Wissensportal: www.baumaschine.de/Portal/ Archive/1_2005/Wissenschaft/lastkollektive/las tkollektive.pdf, 2005.

[11] Siemon A., "Qualitative und quantitative Analysen der linearen und nichtlinearen Schadensakkumulationshypothesen unter Einbeziehung der statistischen Versuchsplannung", Diss., Universität Kassel, Kassel, Germany, 2006-12-21

[12] Palmgren A., "Die Lebensdauer von Kugellagern. " Zeitschrift des Vereins Deutscher Ingenieure 68 H. 14, S. 339-341, 1924

[13] Miner M.A., "Cumulative Damage in Fatigue. ", Journal of Applied Mechanics 12 (1945) Bd. 3, Pages. 159-164, 1945.

[14] Schuster U., "Reliability of hydraulic valves determining the MTTFd value of hydraulic directional control valves.", Customer Benefits of Fluid Power, Internationales Fluidtechnisches Kolloquium, 5, Customer Benefits of Fluid Power, International Fluid Power Conference (IFK), 5 in Fluidtechnik: T; 6; 71-81, 2006

[15] Bobbio A., Trivedi, K. S., Muppala J., "State Enumeration", Reliability and Availability Engineering / 2017, ISBN-10: 1107099501, s.
271-285, Cambridge University Press; Edition 1, 19. Sep. 2017

[16] Nicholls D., Lein P., "Weibayes testing: What is the impact if assumed beta is incorrect?", 2009 Annual Reliability and Maintainability Symposium, Fort Worth, TX, 2009, pp. 37-42.

[17] Abernethy R.B., The New Weibull Handbook, 4th ed., in: R.B. Abernethy (ed.), Florida, USA, 2000.

[18] Baus I., Rahmfeld R., Schumacher A., Pedersen H.C. "Systematic Methodology for Reliability Analysis of Components in Axial Piston Units" Symposium of Fluid Power and Motion Control (GFPS), Sarasota, USA, October 9th, 2019

[19] Zhang, J., Li, H., Fu, J., "Research of Sequential Accelerated Life Test Method for Aviation Gear Pump", Chinese Hydraulics \& Pneumatics, No. 05, pp. 101-104, 2012

[20] Guo, R., Shi, Y., Zhao, J., "Short-time Test Method of Reliability for Hydraulic Pumps", Transactions of the Chinese Society of Agricultural Machinery, No. 03, pp. 405-412, 2016.

[21] Ma, J., Ruan, L., Fu, Y., "A Review on Method of Accelerated Lifetime Test for Aircraft Hydraulic Pump", Chinese Hydraulics \& Pneumatics, No. 6, pp. 6-12, 2015.

[22] ISO 281 "Rolling bearings - Dynamic load ratings and rating life" (ISO 281:2010-10)

[23] Deiters H., "Standardisierung von Lastzyklen zur Beurteilung der Effizienz mobiler Arbeitsmaschinen", Copyright Shaker Verlag 2009, Aachen, ISBN 978-3-8322-8111-3, 2009

[24] Xiao N., Huang H-Z., Li Y., He L., Jin T., "Multiple failure modes analysis and weighted risk priority number evaluation in FMEA", Engineering Failure Analysis, Volume 18, Issue 4, Pages 1162-1170, ISSN 1350-6307, https://doi.org/10.1016/j.engfailanal.2011.02.00 4., 2011 